\title{
Hotel Revenue Management in an Economic Downturn
}

\author{
Sheryl Kimes and Chris Anderson
}

When people talk about revenue management, they typically talk about good economic times in which demand exceeds supply. Indeed, that was the assumption that supported the discussion of revenue management principles in Chapter 14. But as we pointed out in that chapter, this book was written as the United States and the world were recovering from a remarkably deep recession and credit freeze. Consequently, we thought it would be important to discuss revenue management tactics for times when supply exceeds demand, with the continuing goal of selling the right room at the right price at the right time to the right customer, so as to maximize revenue.

As you may painfully recall, the Great Recession was a particularly difficult time for the hotel industry. Hotels recorded widespread drops in occupancies, average daily rate (ADR), and revenue per available room (RevPAR) in 2009. The trade press was filled with articles discussing the downturn and proposing possible tactics for surviving it. ${ }^{1}$ Not surprisingly, hotel owners and hotel operators disagreed on how best to manage rates during that recession as owners tried to maintain sufficient cash flow to cover their costs while operators attempted to maintain service levels and long-term brand equity. ${ }^{2}$

Back in that chapter, we touched on the repeated research, which has shown that hoteliers have to resist the temptation to offer across-the-board price cuts in response to a drop in business. You'll find more about that study in Chapter 15, if you haven't already read that. Instead, you should focus on particular market segments and distribution channels. Even though your rate structure may be relatively transparent because of the Internet, you still can maintain a portfolio of rates, some of them hidden. An ADR is just that, an average, and by managing your rates carefully you should be able to keep your ADR at near or above the average of your competitive set (if that is your strategic goal). As has been mentioned in other chapters, it's hard to increase occupancy enough to make up for having a lower ADR than that of your competitive set. With a relatively lower rate, chances are you will also have an inferior RevPAR performance. This relationship has been shown to hold true across all hotel market levels. Basically, while you may think that you can drive sufficient occupancy by having a lower rate than your competition, the research shows that this doesn't usually work. 
The challenge is how to compete when you are faced with a price war. We believe it's possible for hotels to "intelligently" discount. ${ }^{3}$ Essentially, there are two ways this can be done: through nonprice methods and through price methods. Nonprice methods include competing on the basis of quality, creating strategic partnerships, focusing on your loyalty program, developing additional revenue sources, and developing additional market segments. Price-based methods consist of offering packages, using opaque distribution channels, and offering discounted rates to selected market segments (as we mentioned in Chapter 14). We are not saying that you shouldn't discount prices, but what we suggest is ways to do so that fit your overall strategy and will not kill your ADR. We'll discuss these rate-setting tactics in a moment, after we look at the overall considerations.

A variety of articles and books have been written on the topic of managing price during an economic downturn. ${ }^{4}$ After compiling the findings of this research, we used them in conjunction with the results of a 2010 survey of hoteliers, ${ }^{5}$ which studied the effectiveness of the tactics hotels used during the 2009 economic downturn to develop a concrete set of guidelines that can help you navigate through a price war.

\section{Considerations in a Price War}

When developing a response to a price war, you should assess three factors: (1) your current and potential guests, (2) your hotel and your competitors, and (3) your distribution channels.

1. Your customers. Customer issues that need to be assessed are the price sensitivity of certain market segments and the possible emergence of new segments if new rates are offered. To aim discounted rates at specific price-sensitive market segments, you can develop rate fences that prevent less price-sensitive customers from availing themselves of the discounts as we described in Chapter 14. In addition, you should identify other potential market segments that might be attracted by a selected discount and determine whether it is a market segment that fits in with your hotel's image.

2. Your hotel and your competition. In developing your discount program, you'll want to take into account your hotel's cost structure and market positioning, its capabilities, and its strategic positioning. Hotels with a lower cost structure than their competition can more profitably offer discounts since they may be able to withstand the reduced margins. But you may not want to offer discounts just because you're able. Rates are part of an overall brand proposition, so the type of hotel matters. 
Luxury or upscale properties should exercise great care before discounting because of the potential impact that this could have on the hotel's long-term image. Conversely, budget or economy hotels may not be as affected by a price war because they may benefit from customers "trading down" from more upscale hotels. Their lower prices may appear to offer better value.

The same analysis should be conducted for your competition so as to gauge their potential response to a price war and to determine their strengths and vulnerabilities.

3. Your distribution channels. In addition, you can assess your hotel's distribution channels to determine which ones are most effective at delivering business. Part of that analysis involves whether the volume through that channel would increase if the commission or percentage paid was increased. Opaque channels and distribution channels that offer packages in which your rooms are bundled with other services such as airfare and rental car become even more attractive because they give you an opportunity to obscure your true rate.

\section{What Works and What Doesn't}

Let's start with the nonprice methods for competing in a price war without discounting massively and suffering long-term damage.

Nonprice Methods The six types of nonprice methods that we discuss here are the following: (1) reveal your strategic intentions, (2) compete on the basis of quality, (3) create strategic partnerships, (4) take advantage of your loyalty program, (5) develop additional revenue sources, and (6) develop additional market segments.

1. Reveal your strategic intentions. Let your competitors know what you're planning on doing and operate from a position of strength. If you have lower operating costs or if you have deeper reserves that will allow you to withstand a prolonged price war, let them know it. The airlines do an excellent job at coordinating their actions, as they typically preannounce major pricing actions (e.g., fuel surcharges, baggage fees, fare increases) prior to their implementation, allowing their competitors time to respond in the popular press.

2. Compete on quality. If you are operating in the luxury or upscale segment, you may want to emphasize the quality that your hotel delivers and perhaps even add features (such as personalized stationery, free airport pickup, or fresh flowers) that add 
additional value to your offerings.

Another tactic may be to highlight the performance risks associated with low-price hotels. For example, you could mention the lower service levels and reduced amenities that are provided at your less expensive competitors and contrast that to the superior service offering of your hotel.

3. Create strategic partnerships. Based on your analysis of distribution channels, you can create strategic relationships with particular channels. If you give certain distribution channels a higher commission (whether travel agents or third-party intermediaries), they may be willing to deflect a higher proportion of their business to you. Your costs would go up, but you would not need to cut rates. For example, Booking .com allows properties to have strategic placement at the online travel agent (OTA) for increased commissions - so the property has more prominent display (and increased conversion rates) without having to discount rates.

4. Take advantage of your loyalty program. Reduced demand can also provide your hotel with the capacity needed to reward your loyalty program members. You could, for instance, reduce the number of points needed to redeem a free night's stay for a limited time or make more desirable rewards available. Doing this has two benefits: (1) it brings people into the hotel who may spend money in other outlets, and (2) it keeps loyal guests connected with your hotel. US Airways, for example, offered promotions where travelers could qualify for frequent flyer status with a reduced number of flights. Similarly, certain Hampton Inns offered a "fifth night free" during the winter of $2009-2010$.

5. Develop additional revenue sources. Full-service hotels have a variety of facilities that can be used to generate much-needed revenue. While some of these facilities (most notably, food and beverage) have lower profit margins than rooms, they can still provide additional cash, which can help sustain your hotel during low-demand periods. Creative promotions and discounts may bring more local customers into your restaurants and recreation facilities.

6. Develop additional market segments. An economic downturn is a good time to carefully examine your marketing plan and determine whether there are other market segments that can be developed for your hotel. While this can bring in 
additional revenue and customers for your hotel, care must be taken to ensure that the new market segments fit in well with your brand image.

7. Apply marketing-based approaches. The Internet gives you numerous approaches for creating demand through marketing. When consumers start researching travel possibilities on the Google, Yahoo!, or Bing search engines, you can be ready with a strategy of search engine optimization (SEO) and search engine marketing (SEM). We touched on these strategies in Chapter 14, but let's explore them in detail here. These strategies involve ensuring that consumers find your Web page. SEO is about designing your hotel's Web page such that it places high on the search page. You can do this through properly tagging the pages on your Web site, as well as its images and photos. Your page should contain optimizing terms and phrases making sure that your Web site descriptions and keywords are the ones that consumers are using to search for hotels. Tools such as SEODigger.com can help with this. Make sure your site is linked to important local attractions and agencies. Your Web page needs a site map so the search engine knows how to navigate it. Have pages be consistent and concise-don't have too much information on one page (e.g., have separate pages for your romance package and your fall season preview package). Rather than force people to retrace their clicks, make sure that every page has a booking mask to allow consumers to book whenever they are ready.

For search engine marketing, you bid on keywords and search terms-basically paying to ensure that your Web page gets prime placement on the search pages. Figure 26.1 shows a sample Google search result. As you see, the search page has three areas: local, organic, and paid. A strong SEO strategy should give you a high free placement in the local and organic areas of the search page, while SEM will display your hotel in the paid area. All the search engines provide great tools and analytics to help you effectively bid on keywords and ensure you are making the best use of your search engine marketing dollars. Ideally you want to capitalize on the free clicks from SEO, but SEM is more immediate and may help you drive volume for specific events and arrival dates.

You also need to be reaching out to consumers directly via e-mail. You can do this directly through internal customer relationship management (CRM) efforts or indirectly through firms like 
Travelzoo, which have their own data bases of consumers. Many of the OTAs also have programs where your property can be featured in e-mail offers' they send out to targeted consumers.

\section{Price Methods}

The key strategy in price-related discounting is to avoid instituting across the board rate cuts and instead to either camouflage your discounted rates or target those rates at selected market segments or through certain distribution ' channels. The following are some tactics to execute that strategy:

1. Bundle. As we suggested in Chapter 14, bundling allows you to disguise rates. If you can bundle your room rate in with either additional nights (e.g., stay two nights, get another one free) or with other services at the hotel (e.g., free spa treatment, free Internet), it will help disguise the fact that you are offering lower rates. Restaurants and cruise lines have successfully used this approach for years. Restaurants offer prix fixe meals or value meals in which several courses are offered for one price. Cruise lines use bundling effectively by packaging the cruise with airfare and hotel accommodations. Bundling makes it difficult for customers to determine the prices of the individual components. About 40 percent of the hotel executives who responded to the 2010 survey on successful tactics for surviving an economic downturn had used some sort of bundling tactic and gave high ratings to its effectiveness. Respondents said that they were very likely to use bundling during the next economic downturn. ${ }^{6}$ The key to developing an effective bundle is to determine what your customers want and then deliver it in a profitable manner. Most full service hotels have facilities that are not fully used (e.g., a spa, a golf course, restaurants). By including some of the unused capacity in with the room rate, you do not incur a great deal of incremental cost, can more fully use other parts of your hotel, and have the potential to increase business in these other outlets in the future if guests decide to come back.

2. Unbundle. Depending on your competitive situation, another approach is to base your rate on only your core room product (i.e., a clean room with a bed and bath) and charge additional amounts for any other services that guests might wish to use. Airlines use this approach with their checked-bag fees, and some discount hotels have also adopted this practice. By unbundling, you can keep your base rates relatively low and allow guests to choose which additional services they would like. Although care 
must be taken when using this approach because of the potential damage to customer satisfaction, unbundling may be an option for discount hotels.

Asia-based discount operator Tune Hotels has been using the unbundling approach quite successfully. They charge an additional fee for air-conditioning, for towels, and for Internet use. ${ }^{7}$ Even higher-end chains are starting to impose higher fees. Guests are already accustomed to hotels in many product tiers that charge extra for phone calls and Internet access. Surcharges are expected to amount to US\$1.7 billion in 2010.8

3. Use opaque distribution channels. Opaque distribution channels such as pricehne.com, hotwire.com, and topsecret hotels (known as Lastminute .com in Europe and Travelocity in North America) represent a way in which you can offer discounts while hiding the discount from the customer. They allow you to sell additional rooms while still protecting your rate and brand image. About 50 percent of respondents to the 2010 survey had used opaque distribution channels and considered it to be a highly effective tactic that they would use again. Usage was even higher in the Americas generally, and particularly among three- and four-star hotels. Respondents from five-star hotels were not as enamored with opaque distribution channels, and some were concerned about the potential damage that it might do to their brand image. ${ }^{9}$

4. Offer selected rate cuts. Discounted rates should be provided only to selected market segments. As discussed in Chapter 14, building effective rate fences requires knowing your customers well and understanding what rate fences will be effective in attracting particular market segments. "We noted there the different types of rate fences: room related, transaction related, consumption related, and guest related. Remember also to consider fairness and rate parity issues. Again, common rate fences involve advance purchased restrictions, minimum length of stay restrictions, and more restrictive cancellation fees, thereby limiting the discounts to specific customer segments and also help protect you against potential cannibalization. Finally, ensure that rate cuts are available at the right time. Given today's ease of comparative shopping most properties have similar prices (for the same arrival dates) posted on all channels. This rate parity means that if posted rates are reduced, all customers get these reduced rates regardless of which channel they use to make their 
reservation. Since you cannot segment customers by channel, you need to make sure that you segment by time. Most particularly, you need to be sure that you offer your discounted rate at an OTA when price-sensitive customers are shopping (which is many days before arrival, as we noted in Chapter 14). Then you need to remove this limited-time offer a few days before the arrival date, as indicated by your booking curves.

\section{Advice from the Front Lines}

One of the intents of the study of hotel managers that we mentioned earlier in this chapter was to help you develop a plan for how to approach the next economic downturn. While we all would like to think that a recession won't happen again, we know that it will. So let's prepare to respond to a market downturn in an intelligent and strategic fashion.

Several lessons emerge from the survey results and from the insightful comments that responding hotel executives made. The foremost piece of advice was to be prepared and to have a plan on how to respond to a recession (some people even suggested a standard operating procedure manual). As one respondent stated, "It is never too early to be prepared. You should always have a contingency plan that you can implement within minutes."

When you develop your plan, focus on the long-term and consider the impact that your plan will have on customer satisfaction, employee satisfaction, and the long-term image of your hotel or chain. If you lose sight of the long-term, you may end up compromising customer and employee satisfaction and hurting long-term profitability and viability. As one respondent said, "Maintain the brand image be insistent on the pricing strategy. Focus on your long-term goal and be patient."

Several other lessons emerge from the research:

- Don't panic! Respondents talked about the need to stay calm and look for solutions. One respondent said it quite succinctly, "Do not panic. Do not compare downturn periods with previous good periods. Think more in terms of long-term decisions."

- Be wary of broad-scale discounting. Of the four basic strategies for approaching a future economic downturn, respondents were least likely to recommend discounting. Time and again, respondents discussed how it would take years for their rates to recover from the discounting that they engaged in during the previous year. As one respondent advised: "Don't drop rate-or let me state it this way: don't drop your public/retail rate. Use the retail rate as the benchmark for discount rate programs and 
fence these discounts appropriately." Another made a similar comment: "My advice would be to be very careful about playing the rate-reduction game. In 2007 and 2008, we were very aggressive with increasing our corporate pricing and in the space of a few months all that and more has been undone. We have literally undone three years of solid work in the space of the past eight months. It will take us another three to four years at least to get that back." If you must discount, consider creative packaging and using opaque distribution channels.

- Don't cut your marketing budget. Respondents discussed the need to keep current guests and to develop packages and promotions that attracted both current and potential guests. If you cut your marketing budget, this won't be possible. As one respondent suggested, "When the bad times hit again, save the marketing dollars on new initiatives (e.g., acquiring new customers or promoting new hotels) but focus the spending on the existing customer base."

- Consider marketing approaches. Respondents felt that the development of smaller, less price-sensitive market segments had been highly successful during the recession. As one respondent suggested, "Explore new market segments and new ways of promotions. Try not to drop down rates for all market segments; there are some of them that are not so price sensitive. We have to identify- these guests and work hard to attract them to our property." Another popular and effective tactic was to develop other new revenue streams (such as food and beverage or spa) within the hotel. One respondent summarized this nicely, "We just have to diversify our business rather than rely too heavily on a particular business and geographic segment. At the same time, more emphasis has to be put on how to optimize revenue conversion from all revenue streams be they major or minor, which will ultimately help to improve bottom line." Other tactics that were highly rated were pay-per-click advertising and other Web-based marketing approaches. For example, one respondent said that the hotel planned to rebound by, "Capitalizing on e-channels. We have relaunched our Web site, restructured our URLs for better ranking and organic search in the Search Engines."

- Consider rate-obscuring practices. Remember that there is a difference between your "public" rate and your "private" rate. Focus on how you can develop packages and bundles that add value to the consumer without costing the hotel too much. Consider the following suggestion: "My advice is maintain rate, continue to look for new markets 
(such as religious retreats, romantic weekend packages), develop specials which focus on value added extras like spa treatments, be creative in your food and beverage promotions, and watch for prolonged gaps in occupancy that might be filled with Internet promotions or opaque distribution channels which won't later effect your rate strategy so dramatically." Think about what customers want and try to deliver it without "giving away the house." Also, focus in on packages that are hard to imitate-anyone can offer an extra night for free, so try to develop packages that are unique to your hotel.

Respondents were generally pleased with the performance of opaque "distribution channels. As one respondent mentioned, "Don't drop rate drastically and use opaque distribution systems when you are forced to do so." Conversely, some respondents were concerned about the possible effect on brand image. As one respondent from a five-star hotel stated, "Opaque channel customers are not desirable. They don't want to pay the premium an upper-upscale or luxury charges on services (parking, food and beverages), but expect the moon in return. In the long run, it doesn't cover your costs and often can drive down your GSI."

- Maintain service levels. If you need to cut costs, do so in areas of the hotel that have the least impact on customer service and the hotel image. As one survey respondent said, "Don't reduce standards but add added value; guests are very sensitive to changes. Bad times are not forever, and it could take a longer time to recover if you cut corners to save a buck!" If customer satisfaction and service quality are diminished, it will be more difficult to both maintain your current guests and attract new guests after the recession is over. Consider the following suggestion: "Do not make cost cuts on quality service. It is okay to bring prices down, but set yourself a limit which will not handicap you when you want to bring the ADR up again the following year."

\section{Conclusion}

Economic downturns create pressure to maintain market share, and many hotels were tempted to reduce rate in an attempt to attract additional customers. It is important to realize the limitations of your traditional RM system and its potential inability to properly manage your inventory when demand is less than supply. During a downturn you need to remember that many guests still value your property and are willing to pay a premium to stay with you. You need to be sure to maintain your rate, as often 
the incremental demand generated from a price cut is not enough to offset the rate dilution caused by guests who would have stayed with you anyway (at higher rates). The goal in a downturn to is to reduce your ADR and increase your RevPAR. Nonstrategic rate actions simply reduce both your ADR and RevPAR. If you must offer price cuts make sure they are limited time offers, receive predominant display (typically at the OTA-with a price tag or discount highlight), and are enabled only during the shopping window when price-sensitive consumers are online booking deals. Better yet, use private price reductions. Bundling and packages allow you to provide consumers with deals while, maintaining posted prices. Opaque OTAs offer steep discounts to brand agnostic consumers and provide an ideal forum to reach price-sensitive consumers without having to worry about rate dilution. Last, marketing focused efforts like SEM and e-mail offers that bring consumers to pages with promo code-enabled rates provide another way for you to offer price reductions to consumers who are out there searching for deals (while simultaneously maintaining your regular posted prices). In summary, revenue management involves analytical thinking to create demand and opportunistically fill in weak spots with targeted pricesensitive consumers.

\footnotetext{
${ }^{1}$ For example, see: www.rockcheetah.com/blog/hotel/us-hotel-industry-recession-enters-new-rate-erosionphase/, http://www.occupancymarketing.com/white-papers/marketing_recession.html, asiaone.com/Travel/News/Story/ AlStory20090302-125501.html). ${ }^{2}$ travel.nytimes.com/2009/05/26/business/26hotel.html, http://travelindustry.uptake.com/blog/2009/05/26/owners-brand-hotel-operators/. ${ }^{3}$ S. E. Kimes, "Hotel Revenue Management in an Economic Downturn: Results ' from an International Study," Cornell Hospitality Research Report 9(12) (2009).

${ }^{4}$ For example, see K. B. Monroe, Pricing: Making Profitable Decisions (New York: McGraw-Hill, 2003); R. J. Doland and H. Simon, Power Pricing (New York: Free Press, 1996); A. R. Rao, M. E. Bergen, and S. Davis, "How to Fight a Price War," Harvard Business Review 78(2) (2000): 107-117; and H. J. Van Heerde, E. Gijsbrechts, and K. Pauwels, "Winners and Losers in a Major Price War," Journal of Marketing Research 45 (October 2008): 499-518.

5 . S. E. Kimes, 2010. "Successful Tactics for Surviving an Economic Downturn: Results from an International Study," Cornell Hospitality Research Report 10(7) 2010.

${ }^{6}$ Ibid.

7 . J. A. Siguaw, C. A. Enz, S. E. Kimes, R. Verma, and K. Walsh, "Cases in Innovative Practices in Hospitality and Related Services, Set 1," Cornell Hospitality Research Report 9(17) (2009).

${ }^{8}$ J. L. Levere, "With Airlines Showing the Way, Hotels Are Seeing Big Money in Small Fees," International Herald Tribune (May 5, 2010): 14.

${ }^{9}$ Kimes, 2010
} 